\title{
TOWARDS THE AUTONOMY OF URBAN MANAGEMENT: SIMPLE SYSTEM AS A SOLUTION FOR COMPLEX URBAN ENVIRONMENT
}

\author{
R. BARELKOWSKI ${ }^{1}$, K. BARELKOWSKA ${ }^{2}$, L. CHLASTA ${ }^{2}$, J. JANUSZ $^{2}$ \& L. WARDESKI ${ }^{2}$ \\ ${ }^{1}$ West-Pomeranian University of Technology in Szczecin. \\ ${ }^{2}$ University of Technology and Life Sciences in Bydgoszcz.
}

\begin{abstract}
There was an unprecedented development of cities, both in 19th and 20th century. Especially, late 20th century faced the moment in which urban population exceeded rural population only to accelerate this trend at the turn of the 21 st century. Cities have become extremely fragile, technologically densified, extremely saturated with men and their artifacts, and too much extent very random, chaotic in its emergent patterns, either expanding the city or transforming its existent parts.

Simultaneously, these complex urban patterns encouraged the elaboration of sophisticated systems of urban management. But these systems work only in some areas of the world, most often unable to follow the quick rate of expansion. Therefore, substandard urban areas, undeveloped or overdeveloped, poor areas, segregation, exclusion zones, economically inefficient areas which cannot gain resources to get renovated, refurbished, and renewed.

The work discusses small-scale intervention in chaotic urban areas - Ariadne's Thread system intended to provide signage, telecommunication support, emergency reactive platform with surveillance options, and lighting integrated and dedicated to areas currently having none of these systems appropriately developed. The cluster of pylons connects to permanent local node, compulsory hard infrastructural element. The role of the latter, tasks to perform, the equipment used to analyze signals from cluster and respond in an appropriate manner is a significant supplementing and coordinating hub of the system. This paper will present the structure of the system, its working patterns, and methodology applied.

Keywords: design for communities, development and management, infrastructural systems, planning, sustainability, urban strategies.
\end{abstract}

\section{INTRODUCTION}

Rapid growth of cities worldwide exceeds the ability of many communities to react accordingly and be prepared for such unprecedented scale of simultaneous processes, resulting in expansion and densification of urban tissue, fluctuations in attractiveness, land value, land availability and accessibility, among a myriad of factors. Undoubtedly city can be seen as the pinnacle construct of civilization, the ultimate concentration of highly specialized people, the most sophisticated functions serving the community, infrastructure and transportation systems subservient yet indispensable to the city as an entity. However, its ideal image is being distorted by the forces of society and economy, its growth isn't harmonious and fluent. Sophisticated urban entity, despite all complex systems and tools implemented by various societies in attempts to control and moderate its performance, too often transforms into hardly manageable, unpredictable field of tensions, co-created by contradictory tendencies. While the discourse on sustainable development leads to more advanced theoretical findings and some successful, but local and fractional implementations, the overall result of the processes of urbanization becomes more incompatible with sustainability standards [1]. 
Poor, underdeveloped areas or areas, where rapid development is caused by conditions encouraging chaotic growth, whether it will be typical sprawl of North American or European cities, favelas in South America, or shanty towns in Africa or Asia, provide multiple examples of how cities generate processes which being the result of their temporary success counterbalance many if not all positive achievements. The city is the epitome of tendencies to seize control, manage, regulate, and organize have inherent mechanism, which prevents reaching that status, and which rather cannot be easily overcome by structures acting in top-down modes of operation. As Jean-Claude Bolay describes one of these phenomena - slums, these poor or extremely poor districts of a city are expressions of its nature, and therefore not only every attempt to eradicate them from urban structures failed, but increased social tensions, problems, as well as led to less sustainable parameters of urban environment [2]. When a city cannot withstand a further increase of the inhabitants, quite often they migrate not so far away to connect sub-agglomeration villages and towns closing the gap between agglomeration center and its satellite settlements, eradicating green belts, severing ecological corridors, increasing polluted areas and spreading negative impacts [3]. The reason for this situation, however, is much more complex as Ooi and Phua are attempting to diagnose for Asia - it's not the inability of local authorities to provide affordable housing, healthcare and sanitary conditions [4]. These are nothing, but symptoms of social inability to share environmental assets and inefficiency to provide access to them in an equal way.

\section{AREAS OF INTERVENTION}

Historically, urban management has reached its maturity quite late, in the 19th century, when the foundations for the contemporary theory of Urbanism have been laid. While throughout the centuries, from the ancient times of Varanasi (Benares), Kirkuk (ancient Arapha), Faiyum, or Jericho, cities were devised, designed, founded purposefully, arranged, organized, it was in the 19th century, when cities increased exponentially level of complexity of infrastructure introducing the issues of mass transport, communication, and multiple infrastructural subsoil or suspended networks. Multiplicity of systems affecting the quality of life in urban environment immediately exposed the issue of coherence between the systems.

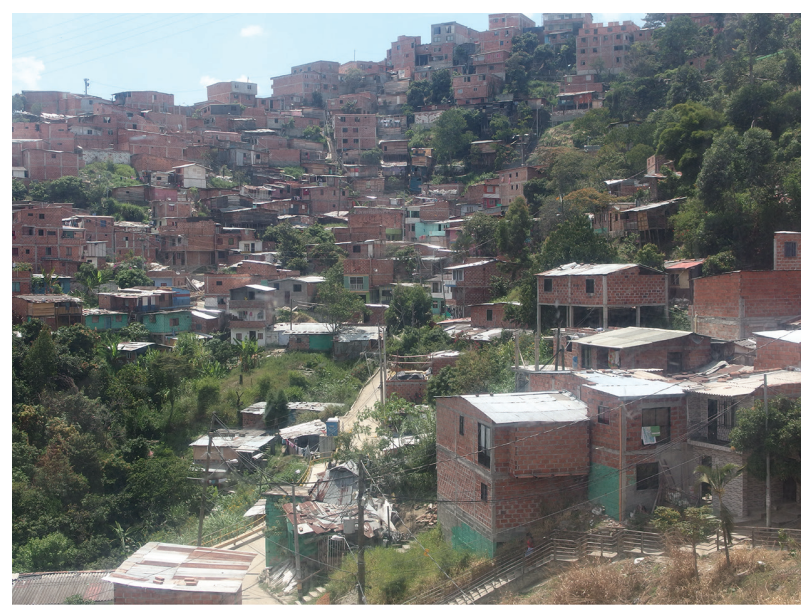

Figure 1: La Quiebra squatter settlement in Medellin, Colombia, photo: RB. 
Contemporary cities have been developing informal settlements for many years, and this process is ongoing and independent of the policies applied by vast majority (if not all) municipalities. Development, as a process directed among administrative bodies and private or corporate owners, offers high rate of unpredictability, resulting in some forms of spontaneous or counter-intentional transformations (from authorities' perspective). Random or spontaneously generated settlements not necessarily form extremely poor environments - their typologies differ depending on culture, geographical and environmental properties, and social behaviors [5]. There are substandard houses or shelters barely giving any protection, but there are also illegal settlements or overdensified and overcrowded areas, or simply improperly maintained urban tissue, now dilapidated and insufficiently fitted out. There are also legal, but unplanned housing areas, emerged from administrative inability to control legal gaps - these settlements, usually chaotic, are perfect examples of chaos inflicted not by the poverty, but by ill-placed thriftiness, seeming "optimization" leading to the devaluation and extensive exploitation of the environment [6]. Some of these settlements or specific districts appear in the central parts of the cities, but the respective majority is observed in peripheral urban areas, called peri-urban zones [7].

The tissues of contemporary cities are dependent on the veins of infrastructure. The capacity and efficiency mark not only the ultimate level of potential densification, but the maturity of the development of urban organism as well. Any attempt to diagnose conditions and quality of life in the city is heavily affected by the quality of infrastructure, which quite often is a primary diagnosed factor of sustainability $[8,9]$, and the rate of infrastructural coherence and integration, which, unexpectedly, is often overlooked.

Informal settlements, shanty towns, favelas, slums are very special areas, in which many parameters discourage planners, designers, and managers from employing standard concepts and typical organization of infrastructure. Low quality of houses or apartments, spontaneously created semipublic spaces unfitted to play its role as integrating spaces, particularly poor materials, which are far

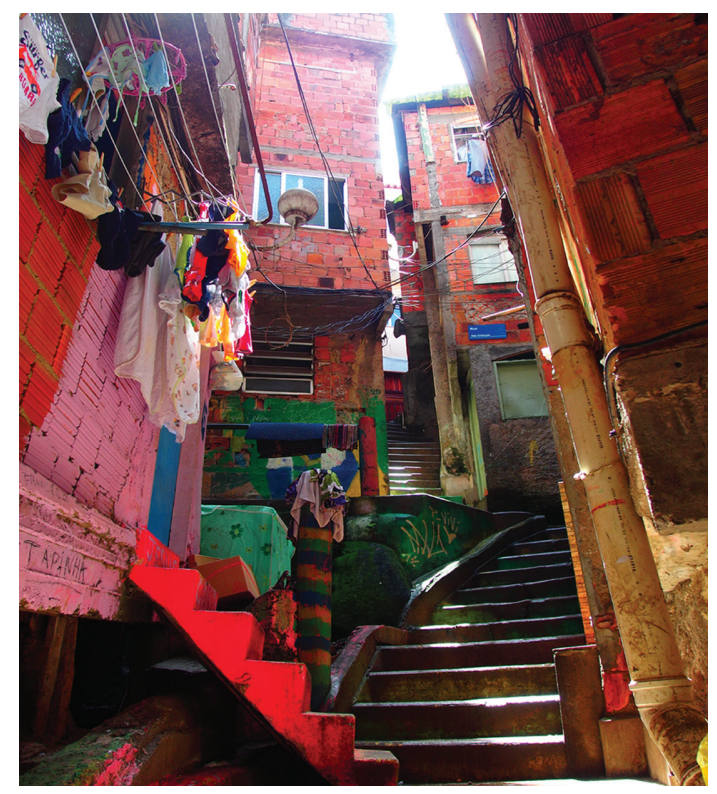

Figure 2: Informal "street” of Santa Marta favela in Rio de Janeiro, photo: RB. 
from being durable, high density and low area per inhabitant - all these factors constitute dense urban habitat with inappropriate, underdeveloped services. There is little room to plan usual spacing for infrastructure, or to provide full scale public squares or sometimes even basic facilities required for local communities [10]. Multiple programs to improve the quality of life in these substandard districts are devised and attempts to implement these programs are underway in countries where above specified problems have become a major issue. The understanding of the necessity to blend these settlements instead of struggling with their emergence and existence has been both the result of inefficiency of previous policies [11] and of the observation that in many cases informal settlements are inherent components of the city not contrary, but because of its nature $[12,13]$.

Contemporary strategies to improve living conditions in shanty towns focus on minimum intervention - maximum effect concept, and hardcore, noncompromising interventions are considered as justified only as extraordinary means to achieve extraordinary goals. As Banerjee et al. see the problem, every settlement has the opportunity to be upgraded, if not transformed, as a result of gradual improvement focused on crucial spaces, which in this case means street network [14]. Seeing truly multifaceted role of the streets one must notice that space here has many "dimensions" in comparison to traditional street - its rich geometry, its ambivalence becomes an immediate vessel to convey meanings, information, interactions, namely more than just communication / transportation. These informal streets or inserted additional streets, build a minimal skeleton - both functional and social - of these parts of the city, what sometimes requires pulling down some structures, an unpopular move, but necessary and acceptable if its scale is moderate to preferred small [15].

\section{ADDING WITHOUT INTERFERENCE}

Street spaces, including those informal ones, provide - obviously - the access to settlements, but these multifunctional corridors quite often have significant impact on privacy, safety, accessibility, availability, and mobility of local community members, to provide but the few possible interpretations of "street interface". Considering any kind of upgrading intervention, one must take into account the impact of any such introduction of any kind of infrastructure within the environment the lesser, the more compact the infrastructure can be. Pearlman, who says, that the investment made in people rather than engineering and architectural infrastructure is always better [16], brings forward important, social argument, but one must not forget, that to aid people it is sometimes necessary to invest in people by investing in the infrastructure, people will be able to benefit from and investing in (architectural) space local community will be able to reclaim, appropriate and use as organizing space for all its members - how otherwise wishes of favelas' inhabitants of having access to health care, schools, or some socializing places can be fulfilled [17].

That is true, that concluding substandard quality of life as being the result of lack of basic services mostly would be naïve, but at the same time what is crucial it is the assessment of negative impacts infrastructural or architectural interventions may have. Assuming they are harmless for the quality of local community ties, its autonomy, its ability to maintain local identity, such a project positively fulfills criteria of "Basic Services for All", the United Nations Human Settlements Programme (UNHSP). Basic services - BS (or unsatisfied basic needs - UBN) which giving the example of India, according to Dhote, Singh and Silakari, include social security among others [18], are not only those, community is aware of - these are also security issues related to regionally considered risks, like landslides in Medellin [19], flooding in Dhaka [20], local administration is responsible.

Many municipalities employ sophisticated management tools to operate the city in an attempt to control its behaviors, to monitor its phenomena. Often GIS systems supported by the commercialization and availability of telecommunication technologies allow the administration to diagnose and react, to collect data, analyze, and plan, at the same time giving the inhabitants access to multiple 
services, mainly making information available for mobile users. IT applications supported by the satellite control facilitate city management and either process information or become an interface to efficiently direct and coordinate any required reactions and municipal service performances. However, this performance may be limited by particular features of geographic environment and significantly hampered by the structure and quality of urban (transformed) environment. Squatted settlements are exceptionally prone to the risk of uncontrollable events and phenomena which may be harmful, if not lethal to local communities, in other cases, these areas are simply hard to be accessed easily in emergency cases. And there is one more significant issue, absent in the majority of urban management systems - its unidirectional structure, limiting the ability to receive social feedback.

But these systems require infrastructure themselves, they are managed independently in an uncoordinated manner (commercial vs municipal), they are fragile and usually disconnected from local lives of communities. Ariadne's Thread is a proposal of an infrastructural system to integrate several spatial and social functions, being used as available-to-all urban system. Its spread and non-serial, autonomous components are highly redundant to maintain connection and services in case of local malfunctioning or damage to the system [21].

\section{SIMPLICITY VERSUS COMPLEXITY}

In case of any urban system, it is unavoidable to implement techniques and subsystems, which are highly dependent on technology, but this technology may successfully tackle two typical problems: high costs of implementation for single-mode system, multilevel hierarchical structure making the system prone to errors, crashes, and similar, and difficulties in use application within diverse social groups, including elderly people, handicapped, youth, or simply foreign to the place and culture, and thus excluded by the lack of appropriate communication skills.

The project is treated as a pilot project, with its first stage focused on the attempt to integrate four main urban systems: signage system, urban lighting, local telecommunication facilitating devices, and security system components. Lighting and security systems (cameras) provide required and often expressed feeling of safety, lighting as well as signage are also crucial for accessibility, telecommunications provide the ability to exchange information, socialize, but also to get informed of significant events, risks, disasters if necessary. This idea of integration of various infrastructural systems is being researched in multiple ways, including that of French [22], whose seemingly correct proposals should be however adjusted to the specificity of every local infrastructural system involved in the process of integration. What's more, despite the fact one may completely agree with the French's idea of joint development of infrastructural systems, at least some of these systems are incompatible: power supply or water distribution. The most important division here is that of inherent permanence of the infrastructure. Technological constraints discard any attempts to abandon the

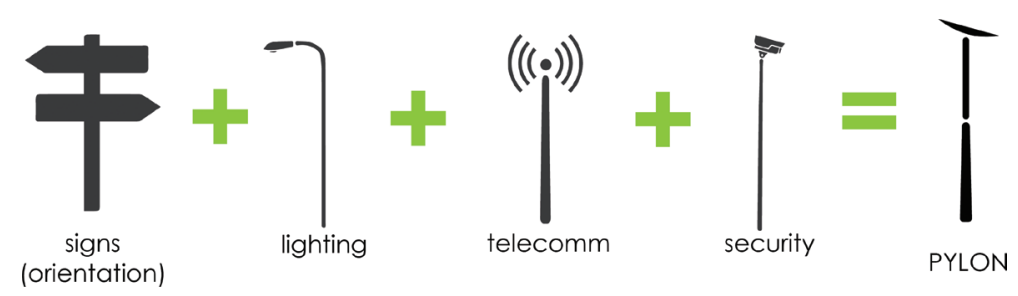

Figure 3: Conceptual scheme of infrastructural integration in Ariadne's Thread. 
typical power supply grid, while other systems, like lighting, particularly in well-isolated regions of the world, may become completely independent of any connecting elements. The concept of reduction the basic component to locally installed single, detached object makes such an object potentially movable, dynamic in use in a sense of retaining the ability to be replaced, transferred to another, site better for optimal performance, to react to changes in the environment (with the help of urban servicemen, of course).

Usually considered permanent, the infrastructure often inadequately adjusts to the new conditions, thus becoming extensively distributed. This increases losses of any system, and complicates fixed, immovable structure. As Gandy notices, a more flexible form of infrastructure is required nowadays, when society is more mobile, and environments change so rapidly [23]. Ariadne's thread relies on the idea of light infrastructure, with local, autonomous devices, mutually amplifying the performance of the system.

The system is supposed to be built with the use of locally centralized facilities and cluster of pylons. The composition of Ariadne's thread physical infrastructure is as follows:

- pylon - basic device, a structure containing basic interactive components of the system,

- cluster - group of pylons operating within a particular area,

- permanent local node (PLN) / center - a privileged location, central for an area; optimally, the best site for location of PLN would allow to host the majority or all emergency / municipal units assuming 5 to 10 minutes reaction time, depending on specific requirements and health and safety analyses,

- base of operations (BoO) - local or a central base of operations in which all events and occurrences may be monitored and reactions directed,

- Ariadne's Thread Hub (ATH) - integrated local infrastructural center composed of PLN, BoO, and additional seats of local service and emergency units; it shall be noticed, that in case of any PLN or BoO malfunction another adjacent ATH resumes the operation instantaneously reconfiguring newly adopted cluster to indicate itself as new center and new reference point.

Ariadne's Thread Hub composed of permanent local node, base of operations, and seats of various municipal units or services is a reconfigurable site. Usually it should provide health care, police station, fire station, environmental and/or infrastructural reaction units. Social program includes

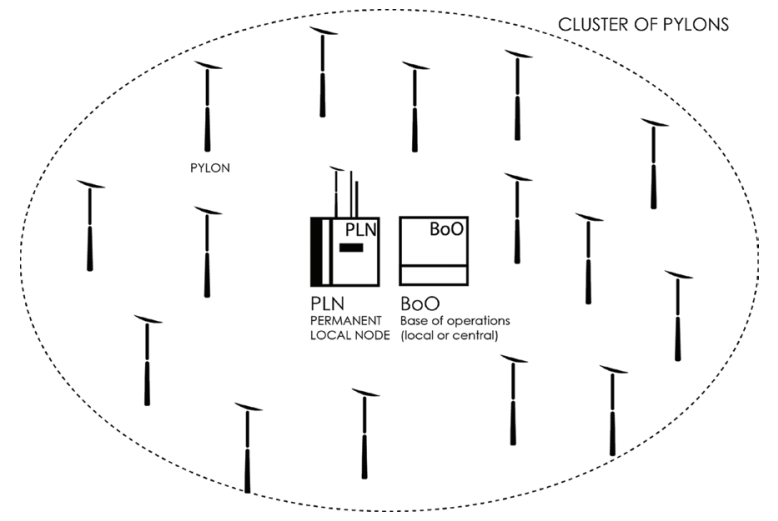

Figure 4: Simple structure of Ariadne's thread system. 


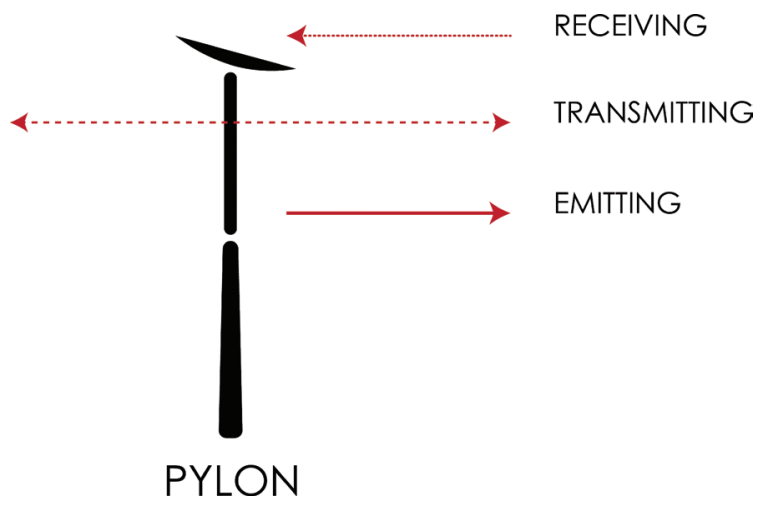

Figure 5: Pylon - Ariadne's Thread basic device modes of operation.

kindergarten, school, library or cultural center, naturally depending on the capacity of the available site, and needs as well as the preferences of the local community. Physical infrastructure, apart from Ariadne's Thread Hub and a cluster of pylons requires selected orientation point - intentionally it is PLN, but it may be substituted by an existing object to be easily visually recognized.

Experiencing the most densest informal settlement brought forward the issue of space availability for pylon location and mounting. The initial concept of only one typology of a pylon seems to be inappropriate and thus, while self-standing pylon remains the default solution. Pylons may take several forms:

- pylon type T - default, standing, foot-based device on reinforced concrete foundation, with steel column supporting dish with POV, cameras, and additional inner equipment,

- pylon type L - devised for narrow spaces and streets, cantilevered and mounted (wall or roof anchored),

- "octopus" (box with receptive and signaling LED-based tentacles) - destined to be mounted in extremely narrow areas or maze-like dense environments.

Pylons are multimodal devices acting as receivers, transmitters, and emitters at the same time. Each one is an independent object, acting as a part of local cluster, a bidirectional vessel for communication between the one emitting signal or initiating signal, and the one that receives the signal. This multimodal performance makes great difference, because when traditional systems of urban management do not require a physical infrastructure and operate based on supervision, on analyzing simulated representations of the city, Ariadne's Thread can not only react, but also communicate. It decentralizes basic municipal services flow of information, and despite its partial dependency on the permanent local node and base of operations.

It could seem that the proposal of AT is more complicated, but the principles of the system to make it less vulnerable to any errors or breakdowns, partially thanks to this particular proposal being a dispersed one, constituted by autonomous, individual devices. When urban space requires a basic infrastructure, it is often built as underground or suspended power cabling, ICT cabling, and piping hidden below roads and streets in these technical corridors of the city. In case of AT system, its simplicity and ability to deliver services through a network of multiple and interchangeable structures and devices. AT has similar ICT elements, but the principal difference lies in ability to move freely parts of the system. 
Ariadne's Thread (AT) is based on the concept of saturating informal or spontaneously created settlements (including those legally designed and built, but being the result of unwanted urban sprawl) with theoretically movable objects with the only part of the system - PLN - as immovable. Naturally, other urbanized areas may be also subject to AT performance. A good example of the application may be seen in environments in which natural changes blur or camouflage spatial distinctions. Similarly, it can be used in overdeveloped high-density residential estates where the introduction of infrastructure has been delayed. Economic conditions for the use of AT system is to have affordable, if not cheap, the components being able to evolve according to the needs of the community, supporting emerging districts risen as a result of urban sprawl, assuming the authorities were unprepared for this rate of development. Informal settlements increase costs of a standard infrastructure and thus make it extremely difficult to supply the inhabitants contrary to autonomous components of AT. Flexibility of Ariadne's Thread is directly converted into a potentially autonomous status of community, whose members live in the area, contributing to self-awareness, social activity, and cooperation. The system broadcasts signals within the urban environment and increases social ties - emergency calls encourage people to help others, make them more sensible and aware of the fact that something significant happens in the area. Signals are much easier delivered to multiple users.

Information is transferred by different ways. First of all, there is a mobile application working with smartphones. Easy to use application provides the opportunity for registered users to inform others on any risk or danger, to alert municipal services in emergency case, by simple selection of the option. However, this mode of operation is currently achieved without necessity to use AT system. In fact, AT is more oriented toward working within urban space, to avoid excluding e.g. technically inapt persons, elderly people who don't use modern communication tools. Thus, the use of credit card (as identification, not as payment device) also allows to trigger signals on the pole, directly, and in the case of type L pylon, by signal-box located within reach of any person on the street or an urban square.

Exemplary cases to use the system may be described as fire case scenario, in which two various modes of pylon reaction may be triggered, or police call, or environmental disaster evacuation route indication. The signal is processed by the system in a following way:

\section{stimuli response $>$ recognition $>$ decision making / activation $>$ processing}

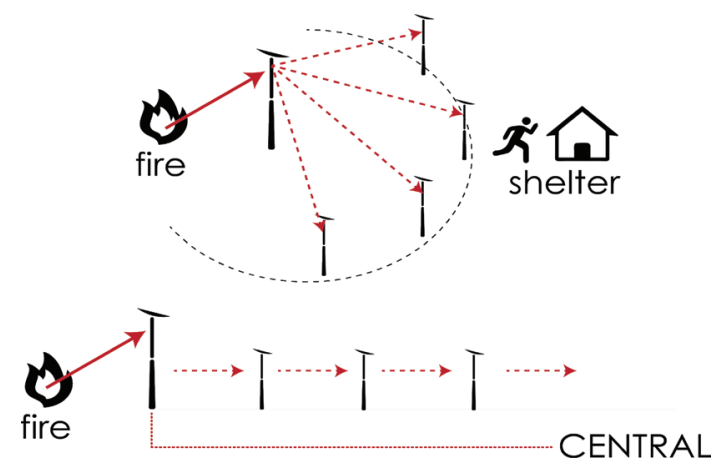

Figure 6: Fire case scenario - cluster of pylons modus operandi scheme. 
and the cluster may work in a centripetal way, sequential way leading emergency unit to the required place, sequential in an opposite way, when the user is to be expected and helped in base of operation. It may also work in zonal mode, particularly in case of environmental hazards.

\section{CONCLUSIONS}

Ariadne's Thread is currently more of a proposal of a system, than something that could be fieldtested. Its performance, however, may be easily simulated and consulted with local communities, because it does require as little physical connections as possible. Weinstock and Gharleghi argued that the contemporary city must be (entirely) reactive and responsive, adjusting its structure to urban flux, to changes in time-space, and the AT system is a step toward these principles [24]. Despite the technical inclination of equipment used in a pylon, system is relatively simple, yet it may be easily plugged-in into urban management systems, acting semi-independently. It is also a great lesson in the design process, as well as methodological aspects of joint reflection on particular environmental qualities of informal settlements. Information technology becoming more private issue results too often in alienation, social insensitiveness - therefore AT focuses on visibility, simple signs that are recognizable by the majority, if not all members of the local community, and let people act and also being judged for their actions or inactions. Marginalized slums, favelas, and squatter settlements are good reminders of how people can overcome disparities, how they are determined despite discouraging conditions - and for them simple solutions should be designed and made available.

\section{REFERENCES}

[1] Bithas, K.P. \& Christofakis, M., Environmentally sustainable cities: critical review and operational conditions. Sustainable Development, 14, pp. 185-187, 2006. http://dx.doi.org/10.1002/sd.262

[2] Bolay, J.C., Slums and urban development: questions on society and globalization. The European Journal of Development Research, 18(2), pp. 287-289, 2006. http://dx.doi.org/10.1080/09578810600709492

[3] Ooi, G.L. \& Phua, K.H., Urbanization and slum formation. Journal of Urban Health: Bulletin of the New York Academy of Medicine, 84(1), pp. i28-i29, 2007.

[4] Ibid. (30).

[5] Tsenkova, S., Self-made cities. In Search of Sustainable Solutions for Informal Settlements in the United Nations Economic Commission for Europe Region, United Nations Publications: New York and Geneva, 2009.

[6] Ibid. (16-17).

[7] Nilsson, K., Nielsen, T.S., Aalbers, C., Bell, S., Boitier, B., Chery, J.P., Fertner, C., Groschowski, M., Haase, D., Loibl, W., Pauleit, S., Pintar, M., Piorr, A., Ravetz, J., Ristimäki, M., Rounsevell, M., Tosics, I., Westerink, J. \& Zasada, I., Strategies for sustainable urban development and urban-rural linkages, research briefings. European Journal of Spatial Development, 2014.

[8] Ajayi, O.O., Oviasogie, F.O., Azuh, D.E. \& Duruji, M.M., Urban design and sustainable development: a case of Makoko area of Lagos State, Nigeria. European Scientific Journal, 2, pp. 90-91, 2014.

[9] Ali, M.H. \& Sulaiman, M.S., The Causes and Consequences of the Informal Settlements in Zanzibar, Shaping the Change, XXIII FIG Congress Munich, Germany, pp. 1-5, 2006.

[10] Marx, B., Stoker, T. \& Suri, T., The Economics of Slums in the Developing World. Journal of Economic Perspectives, 27(4), pp. 192-193, 2013.

http://dx.doi.org/10.1257/jep.27.4.187 
[11] Pearlman, J., Favela. Four Decades of Living on the Edge in Rio de Janeiro. Oxford University Press; New York, 74-77, 268-271.

[12] Xavier, H.N. \& Magalhaes, F., The case of Rio de Janeiro. Understanding Slums: Case Studies for the Global Report on Human Settlements, 21-24, 2003.

[13] Godwin Premsing, J. \& Philip, S., Improving living conditions in Slums Dwellers. IOSR Journal of Humanities and Social Science, 19(6), pp. 63-64, 2014.

[14] Banerjee, B., Acioly, C., Gebre-Egziabher, A., Clos, J. \& Dietrich, K., Streets as tools for urban transformation in slums: a street-led approach to citywide slum upgrading. UN-Habitat Working Paper, United Nations Human Settlements Programme, UNON, 13-15, 18-22, 2012.

[15] Ibid. (22).

[16] Op. cit., Pearlman (2010: 22).

[17] Ibid. (84).

[18] Dhote, K.K., Singh, P.O. and Silakari, R., Social implication assessment framework for basic services to an urban poor program in India. In The Sustainable City VIII. Urban Regeneration and Sustainability, eds. S.S. Zubir \& C.A. Brebbia, WIT Transactions on Ecology and the Environment, Vol. 179, Wessex Institute of Technology, WIT Press, Southampton \& Boston, 1321-1330, 2013.

[19] Restrepo, A.E. \& Orsini, F.M., Informality and Social Urbanism in Medellin, in M. Hermelin, A. Echeverri and J. Giraldo (eds.), Medellin: Environment, Urbanism, and Society, Universidad EAFIT, Fondo Editorial, 148-149, 2010.

[20] Jabeen, H., Johnson, C. \& Allen, A., Built-in resilience: learning from grassroots coping strategies for climate variability, Environment \& Urbanization, 22(2), pp. 419-420, 2010.

[21] Barelkowski, R., Designing Ariadne's thread for the urban maze, 10th International Conference on Design Principles and Practices, Common Ground Publishing + Pontificia Universidade Catolica de Rio de Janeiro, Rio de Janeiro, pp. 12, 2016.

[22] French, S.P., Designing more sustainable cities by integrating infrastructure systems. In N. Marchettini, C. A. Brebbia, R. Pulselli and S. Bastianoni (eds.) The Sustainable City IX. Urban Regeneration and Sustainability, Vol. 1, WIT Transactions on Ecology and the Environment, Vol. 191, Wessex Institute of Technology, WIT Press, Southampton \& Boston, 507, 2014.

[23] Gandy, M., Urban flux. Architectural Design, Vol. 79, No. 5, Profile No 201, Sep/Oct 2009, 14-15, 2009.

[24] Weinstock, M. \& Gharieghi, M., Intelligent cities and the taxonomy of cognitive scales. Architectural Design, No. 4, Profile No 224, Jul/Aug 2013, 60-62, 2013. 